\title{
Motivation as the Contrast Feature in Language Learning Theories
}

\author{
Sana Khudhur \\ Department of Intercultural Linguistics, School of Humanities, Eotvos Lorand University, Budapest, Hungary \\ Email address: \\ San_soul@yahoo.co.uk \\ To cite this article: \\ Sana Khudhur. Motivation as the Contrast Feature in Language Learning Theories. International Journal of Applied Linguistics and \\ Translation. Vol. 3, No. 4, 2017, pp. 46-49. doi: 10.11648/j.ijalt.20170304.11
}

Received: April 27,2017; Accepted: May 6, 2017; Published: October 18, 2017

\begin{abstract}
Motivation has been the hot topic of debates and discussions by researchers and psychologists for many years. It has mostly been regarded as the key factor in energizing and directing human actions and finally responsible for human behavior. In language learning theories, motivation has also widely accepted as the most influential attribute in determining language learning accomplishments. Though, various theories of language learning proposed diverse views concerning motivation which were more or less related to each other. It has been manipulated and explained in different ways based on time emerging of such theories and the attitudes of scholars that were presented within different time intervals. This study tries to examine the contrastive views of motivation based on two language learning theories, namely behaviorism and communicative language teaching approach. It has provided theoretical argumentation on the role of motivation in language learning based on the two theories, how it has been observed or understood in different ways over time and how affects learners in language learning process.
\end{abstract}

Keywords: Motivation, Behaviorism, Operant Conditioning, Classical Conditioning, Communicative Language Teaching

\section{Introduction}

Language is a way of communication. Lacking of basic skills of communication causes unimpressive contact among people. Therefore; obtaining essential skills to communicate is a matter of must. This study refers to two approaches of language learning (Behaviourism and Communicative Language Teaching) in such a way that they presented different ways of learning. Here, the key principles of the two approaches, the origins and their aims despite the view of motivation from both approaches` point of views are discussed.

\section{Behaviorism Theory of Language Learning}

Behaviorism refers back to early 20th century, when psychologists focused on 'self-analysis of mental process'. Meanwhile; behaviorist thinkers (namely Skinner, Ivan Pavlov and John Watson) developed the structure that emphasized obvious processes. In this way, the consequences lead to commence a new approach which was behaviorism. It grew for the first fifty years and became the basic source of tentative researchers. Although some psychologists turned to other approaches later; this was because of its restrictions, namely for the reason that behaviorism focused mainly on behavioral processes with disregard to mental state; whereas it has still its own impact. (O`Donohue \& Kitchener, 1999)

In theory, the term is related to what is observed in environment and from behavior of individuals. It can be acquired in a systematic and observable manner with no considerations for internal perceptions or mental states such as thought or belief. It has based on the idea that only visible actions should be considered. This theory deems that what individuals get from the environment stimulates their behavior clearly (see Skinner, 1957 and 1965; O`Donohue \& Kitchener, 1999 and Richards and Rodgers, 1999).

Behaviorism equates learning with the repetition of observable performances with little or no changes. Behaviorists claim that learning is achieved only when a proper response showed after providing explicit stimulus. The theory only focuses on the consequences of the stimulus, which is a proper response to it in the future with disregard to learner knowledge; nor the assessment of necessary mental processes. The learner is 
only expected to reactivate (or respond) to the provided stimulus without having any role in discovering that response (More could be seen in O'Donohue and Kitchener, 1999; Baum 2005 and Ertrner and Newby, 2013).

One of the key features of behaviorism that most of the scholars found in their studies is that it maintains behaviors through conditioning and interaction with the environment. Therefore, behaviorist thinkers, according to Skinner (1957) and Ellis (1997), paid a great attention to this aspect and distinguished two main types of conditioning:

1- Classical conditioning: it is a behavioral technique in which a natural habit is corresponded as a response of a natural stimulus.

2- Operant conditioning: (also called instrumental conditioning), it is a method in which connected basically with a reward or punishment in respond to a behavior.

In addition to the two types of conditioning discussed above, Harmer (2007) views that conditioning also is [the result of a three-stage procedure] those indicate; stimulus, response and reinforcement.

Behaviorism has a particular viewpoint of learning and teaching. Ellis (1997: 31) found that "According to this theory, language learning is like any other kind of learning in that it involves habit formation. Habits are formed when learners respond to stimuli in the environment and subsequently have their responses reinforced so that they are remembered". The principles of behaviorism, according to behaviorist scholars, can be extremely important in simplifying learning within the class as it primarily considers imitation. Individuals usually earn their behavior by watching a model in the environment and emulating. The importance of this principle is that individuals learn behavior through observation and imitation. For example, the child start imitating adults and adults imitate each other. The goal is achieved by the strong desire of individuals to imitate and the preferred behavior attained through observation (Driscoll, 2000). It also depends on attention, conversation and the restoration of actions. When individuals observe a behavior in an environment, their needs require them to repeat the same behavior as a response to their surroundings. Therefore; the goal could be targeted and in this way learning happens.

In brief, there are mainly two range objectives of behaviorism as Richards \& Rodgers (1999) argued. Shortrange, which is the identification of listening or speech practices and ability to change them into writing skill and the long-range objective, that is to use language as native as possible. This clarifies that the focus in the early stages of behaviorism was on oral skills which equated with accurate pronunciation and grammar and also the ability to respond quickly and fluently in communication situations, with gradual links to other skills as learning develops.

\section{Communicative Approach of Language Learning}

Unlike behaviorism, communicative language approach applied real-life situations to language teaching and learning that imposes communication. It leaves learners in anticipation to produce class implementation that will differ according to their requirements (McDonough \& Shaw, 2003).

Interests in the use of communicative language approach flourished in (1970s) as authentic language and various classroom activities replaced other methods of language learning. Accordingly, learning foreign language was widely desired. As a result, teaching methods and even syllabuses needed to be changed to suit the requirements of new learners. Because the traditional grammar and translation methods of teaching were deficient and emphasized by insignificant structures and mainly focused on repetitions (Richards and Rodgers, 1999; Littlewood, 2002); new syllabuses used to fulfill the needs and achieve the goal of learning of the target language.

It could be argued that communicative approach introduced as a product for educators and linguists who were not satisfied with the prior methods. Scholars claimed that learners would not get realistic language and could not communicate with a proper language depending on the previous methods. Therefore, they will be in lack of using the cultural aspects of the target language appropriately (Savignon \& Berns, 1987). Additionally, since communicative language approach considers language as [a way of communication]; learners have something to share or discover (McDonough \& Shaw, 2003). For this reason, it comprises all various functions of language, in terms of asking for information, expressing feeling or giving permissions. In addition to involving language functions; it clears the way to teaching a range of other important subjects or situations besides the classroom activities that give learners opportunity to use language and pay attention to meaning rather than form.

This approach also prefers messages behind doing the task in a communicative way in favor of correcting the structures. Hence, it is much more learning as it is determined by learners` requirements and advantages. That is, learners need to be able to encounter in foreign contexts and cope with the reality of daily issues. The class of communicative language teaching approach is described as an active style of learning and various techniques and methods of teaching, such as pair work or group work, are ideally more essential than exploiting the class by the teacher as it could be observed in traditional ways of teaching. That means, learners have self contact with language by oral or listening skill practices, including practicing sounds or working on sentence patterns, to get the possibility to make mistakes and eventually learn from them. Whereas this does not mean communicative approach disregarded other skills like reading or writing. It has moderately confirmed them as the way to develop and promote learners confidence with different varieties and activities of skills. To be more precise, paraphrasing, discussion or translation are used to make language more competent and allow learners to manipulate language more confidently (Richards and Rodgers, 1999).

Given that communication based on grammar; 
communicative approach teaches grammar alongside with other language uses in an innovative approach, but less systematically. This leads to a breakdown of language in communication as learners need to hear as much as possible about the subject language at regular time intervals instead of passive acquisition of the items.

Communicative approach almost all the times personalises the activities and adopts individual interests since evocative language is easier to preserve by learners. Despite the use of idiomatic; everyday expressions and colloquial language items are also frequent. These are supportive for learners to communicate as well as practice topics that involve daily life issues or familiar habits (Ertmer and Newby, 2013).

Communicative approach aims simply to lead learners into interaction, involve in real life communication and keep them to use language appropriately. It considers language in a broader means of structures, such as grammar or vocabulary and rather, observes language in ways of its performance and communicative functions (Littlewood, 2002).

Therefore, we can conclude that communicative language approach is a set of principles, as Richards (2006) underlines, which determine the goals of teaching and the ways of active learning.

\section{Motivation as the Contrast Feature of the Two Theories}

There are bunches of definitions with regard to motivation in language learning (for recent studies on motivation find Dornyei and Ushioda 2011 and Dornyei and Otto, 1998). This study adopts Ellis's identification for motivation which he defined as an attempt that drives learners in to language learning. It is sustained by learner's desire for learning. He elaborates that "Motivation is dynamic in nature; it is not something that a learner has or does not have. But rather something that varies from one moment to the next depending on the learning context or task" (1997: 76)

In behaviorism theory, motivation has unconsidered and it has no obvious value. Behaviorist scholars namely (Skinner and Watson) did not pay enough attention to this affective factor in language learning because they thought that behaviorism does not account for thoughts and the only favorable thing for them was action. In Skinner's view (see Skinner, 1965), verbal behavior confuses under the imperfect control of motivation and it might be 'forgotten' because insignificant actions by motivation might make behavior worthless and this leads to "unchecked repetition".

Skinner's theory is basically based on operant conditioning which believes that consequences follow stimulus and the nature of behavior pushes organisms towards the repetition of the same behavior. Thus, a behavior caused by stimulus which results in increasing probability of having the same behavior in the future.

The first Russian behaviorist thinker Ivan Sechenov (18291905) in his work (Reflexes of the Brain, 1965) denied that behaviors caused by thoughts. He agreed with Skinner's view in respect that all behaviors are results of external stimulations and argued that thoughts are inconceivable without stimulation. In this, the way he thought and made up his mind regarding motivation was true; whereas in reality, the way he could apply motivation to individual's action was doubtful because behavior could not be restricted by having external stimulus only but rather thoughts might be the source of actions.

In contrast to what has reached above concerning the attitudes of behaviorism theory with regard to learner behavior and motivation; communicative language approach followers encourage learners to initiate and involve in communication and discover things by their own rather than concentrating on rules or being precise. They believe that correction is not necessarily needed; the only goal to achieve is to lead the learners to converse and exchange ideas. Communicative approach is not just about the "repetition or drilling" (Larsen-Freeman, 1986), but rather it is motivating. It motivates learners to rehearse real life activities and present opportunities that lead to real communication such as telephone communication, video or TV programs, all of which can be demonstrated in different ways. McDonough and Shaw (2003) represent various scholars`argumentations concerning this approach and come to the result that learners need to be motivated in order to be competent in language. Therefore; they believe that it is communicative approach that supports learners to acquire language appropriately since it enables them to get both knowledge and the proper use of language simultaneously.

Further explanations also provided concerning behaviorism theory with regard to motivation. For instance, Ellis (1997) finds that behaviorist learners will learn only if they imitate a model using correct language. In this, they will obtain "positive reinforcement". For this reason, it can be argued that, behaviorism is not an adequate approach in acquiring second language because the way that learners reproduce is not always the same as the one that the model has performed. Learning is not only the repetition or reaction to the "external stimuli" but rather it is the way of creating and working with language in an inspired way as it has claimed by communicative approach. Dissimilar to behaviorism, communicative approach motivates learners to use language impulsively and creatively. The supporters of this approach would only mind in active communication, no matter what errors learners are making while involving in communication.

Another point to add is that, in behaviorism approach the center of focus is teacher. Behaviorists thought that the teacher must control learners and should hold all the necessary roles in learning process. Therefore; motivation remains far from having a role or consideration since behaviorism deems that anything incompatible with the theory should be prevented. Unlikely, the learner centers the focus of attention in communicative language learning approach and teacher's role remains only as a "facilitator" to lead learners become independent. It was also claimed that "The teacher has two main roles: the first role is to facilitate 
the communication process between all participants in the classroom, and between these participants and the various activities and texts. The second role is to act as independent participant within the learning-teaching group" (Breen and Candin, 1980: 99)

In other respects, while behaviorism maintains that motivation is only based on interest of the structures of language learning; communicative approach confirms that motivation will rise from anything that is appropriate for communication. According to behaviorist thinkers each time the learners were presented a new subject, they would have to practice the structure of that specific subject with no further practices that were away from the study material, namely course book. In opposition to this hypothesis, communicative theory seeks using authentic resources in view of the fact that it is more motivating and appealing. It also tends to provide an alternative native speaking community for learners. What's more; communicative approach aims to use coursebooks in the class in a communicative way and manipulate as a base of inspiration. Though that does not mean that learners are bounded to a designed coursebook as we might see in behaviorism; but rather, it renders more communicatively. Based on this, students would have clear ideas that learning materials are motivating and stimulate them into active practice and arouses their interests.

To sum up, materials should be fresh and realistic. They should help learner to cope with unanticipated situations in a communicative way not like behaviorism that prohibits using real life contexts.

\section{Conclusion}

To conclude, language is the way to interact and it has a clear association with society. The study of language learning has to look at the functions of language in two different contexts, linguistic and social context. The former intends to discover the expressions that occurred before and after involving in a conversational situation. While the latter aims to find out who is the speaker, what is his social role and what leads to involve in communication and perform a behavior (Savignon and Berns, 1987).

Theories of language learning have appeared and sustained in times of variable needs for language learning, communicating and understanding. In this respect, both behaviorism and communicative language approach have provided reasonable hypotheses regarding the issue of language learning and had their own significance during the time of their emerging. It can be argued that each have given wide approval and reasonable diagnosis in terms of language learning. Motivation, on the other hand, by no means is one of the basic factors of language learning. It has been argued that it is the cause and the result of language learning success. Together, behaviorism and communicative approach as discussed in this paper offered various contrasting points on the subject of motivation and considered the importance and the role of motivation in language learning in different viewpoints.

\section{References}

[1] Baum, W. (2005) Understanding Behaviorism: Behavior, Culture, and Evolution (2nd ed.) Oxford: Blackwell.

[2] Breen, M. and Candlin, C. (1980) The essentials of a communicative curriculum in language teaching. In Richards, J. and Rodgers, T. (2001) Approaches and Methods in Language Teaching Cambridge: Cambridge University Press.

[3] Driscoll, M. (2000) Psychology of Learning for Instruction (2nd ed.) Boston: Allyn and Bacon.

[4] Dörnyei, Z. \& Ottó, I. (1998) Motivation in action: A process model of L2 motivation. Working Papers in Applied Linguistics 4, 43-69.

[5] Dörnyei, Z. \& Ushioda, E. (2011) Teaching and researching motivation. London: Longman.

[6] Ellis, R. (1997) Second Language Acquisition. Oxford: Oxford University Press.

[7] Ertmer, P and Newby, T. (2013). Behaviorism, cognitivism, and constructivism: Comparing critical features from an instructional design perspective. Performance Improvement Quarterly, 26(2), 43-71.

[8] Harmer, J. (2007) The Practice of English Language Teaching (4th ed.) London: Longman.

[9] Larsen-Freeman, D. (1986). Techniques and Principles in Language Teaching. Oxford: Oxford University Press.

[10] Littlewood, W. (2002). Communicative Language Teaching: An Introduction. Cambridge: Cambridge University Press.

[11] McDonough, J. and Shaw, C. (2003) Materials and Methods in English Language Teaching. (2nd ed.) Oxford: Blackwell.

[12] O'Donohue, W. and Kitchener, R. (1999) Handbook of Behaviorism. U.S.: Academic Press.

[13] Richards, J. and Rodgers, T (1999) Approaches and Methods in Language Learning. Cambridge: Cambridge University Press.

[14] Richards, J. (2006) Communicative Language Teaching Today. Cambridge: Cambridge University Press.

[15] Savignon, S. and Berns, M. (1987) Initiatives in Communicative Language Teaching. Reading: MA AddisonWesley.

[16] Sechenov, I. (1965) Reflexes of the Brain. U.S.: Mit Press.

[17] Skinner, B. (1957) Verbal Behavior. New York: AppletonCentury-Crofts.

[18] Skinner, B. (1965) Science and Human Behavior USA: The free Press. 